\title{
Associations of serum 25-hydroxycholecalciferol and parathyroid hormone with serum lipids differ by sex and vitamin D status
}

\author{
Alexandra Jungert ${ }^{1}$, Heinz J Roth ${ }^{2}$ and Monika Neuhäuser-Berthold ${ }^{1, *}$ \\ ${ }^{1}$ Institute of Nutritional Science, Justus-Liebig-University, Goethestrasse 55, D-35390 Giessen, Germany: \\ ${ }^{2}$ Limbach Laboratory, Department of Endocrinology and Oncology, Heidelberg, Germany
}

Submitted 17 February 2014: Final revision received 21 July 2014: Accepted 16 September 2014: First published online 30 0ctober 2014

\begin{abstract}
Objective: Although emerging evidence indicates an association between vitamin D and serum lipids, the data are still inconsistent. The purpose of the present study was to investigate whether 25-hydroxycholecalciferol (25-hydroxyvitamin $\mathrm{D}_{3}$; $\left.25(\mathrm{OH}) \mathrm{D}_{3}\right)$ or intact parathyroid hormone (iPTH) was independently related to serum lipids in elderly women and men.

Design: Cross-sectional study. Fasting serum levels of $25(\mathrm{OH}) \mathrm{D}_{3}$, iPTH, TAG, total cholesterol (TC), HDL cholesterol (HDL-C) and LDL cholesterol (LDL-C) were assessed. Body composition was measured by bioelectrical impedance analysis. Lifestyle factors, such as nutrient intake, time spent outdoors, physical activity, smoking, supplement intake and medication, were assessed by questionnaires. Multiple regression analyses were performed to examine associations of $25(\mathrm{OH}) \mathrm{D}_{3}$ and iPTH with serum lipids.

Setting: Giessen, Germany.

Subjects: One hundred and ninety-three well-functioning German elderly aged 66-96 years.

Results: After adjusting for age, body fat, physical activity, smoking, alcohol intake, lipid-modifying drugs and either iPTH or $25(\mathrm{OH}) \mathrm{D}_{3}, 25(\mathrm{OH}) \mathrm{D}_{3}$ was a predictor of TAG (standardised coefficient beta $(\beta)=-0 \cdot 180)$, HDL-C $(\beta=0 \cdot 197)$, LDL-C:HDL-C $(\beta=-0.298)$ and TC:HDL-C $(\beta=-0.302)$ in women, whereas iPTH was a predictor of HDL-C $(\beta=-0 \cdot 297)$ in men. In sub-analysis, associations between $25(\mathrm{OH}) \mathrm{D}_{3}$ and TC $(\beta=-0 \cdot 252)$, HDL-C $(\beta=0 \cdot 230)$, LDL-C $(\beta=-0.324)$, LDL-C:HDL-C $(\beta=-0.412)$ and TC:HDL-C $(\beta=-0 \cdot 380)$ were found in women with $25(\mathrm{OH}) \mathrm{D}_{3}$ concentrations above or equal the median vitamin D status $(62.3 \mathrm{nmol} / \mathrm{l})$, but not in women with lower $25(\mathrm{OH}) \mathrm{D}_{3}$ concentrations.

Conclusions: In the elderly, associations of $25(\mathrm{OH}) \mathrm{D}_{3}$ and $\mathrm{iPTH}$ with serum lipids may differ by sex and may require a vitamin D status above $62 \mathrm{nmol} / \mathrm{l}$.
\end{abstract}

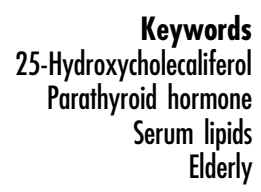

Accumulating epidemiological data indicate that vitamin D deficiency may be accompanied by susceptibility for chronic diseases $^{(1)}$. Recently, a low vitamin D status has been linked to increased serum levels of TAG, total cholesterol (TC) and LDL cholesterol (LDL-C), as well as low concentrations of HDL cholesterol (HDL-C) ${ }^{(2-8)}$. Parathyroid hormone (PTH), which increases in the presence of vitamin D insufficiency, was also linked to serum lipids ${ }^{(9)}$. However, the results are inconsistent and associations often vanished after controlling for confounding variables ${ }^{(5,6,8)}$.

The question arises whether the assumed associations between serum lipids and vitamin D and PTH are independent from other cardiovascular risk factors like obesity, which has been associated with elevated serum lipids ${ }^{(10)}$ and may also interfere with the vitamin D endocrine system ${ }^{(11)}$. In addition, the associations may differ by sex considering the differences in body composition and serum lipid levels between women and men. Previous studies were mostly performed on ambulatory patients and/or vitamin Ddeficient, middle-aged or overweight and obese individuals and often without adjustments for potential confounders, such as the association between vitamin D and PTH, body composition, medical conditions and/or lifestyle factors, including sun exposure, physical activity and habitual diet ${ }^{(4-7,9,12-15)}$.

As dyslipidaemia is an important CVD risk factor and an established component of the metabolic syndrome, treatment and prevention strategies are of particular importance ${ }^{(16)}$. This applies especially to elderly people, who are at risk of developing dyslipidaemia. Moreover, an advanced age is linked to vitamin D deficiency because of age-related declines in endogenous vitamin D synthesis, sun exposure 
and dietary intake ${ }^{(17)}$, which in turn may lead to a rise in PTH. However, studies in which the associations of vitamin D and PTH with serum lipids and lipid ratios are simultaneously examined in well-functioning elderly persons are scarce.

The objective of our study was to analyse whether vitamin D status, as measured by serum 25-hydroxycholecalciferol (25-hydroxyvitamin $\mathrm{D}_{3} ; 25(\mathrm{OH}) \mathrm{D}_{3}$ ) levels, and the levels of intact PTH (iPTH) are related to serum lipids and lipid ratios in non-institutionalised elderly people. Thereby, we took into account that these associations may depend on sex, age, body composition or lifestyle. Furthermore, as some experts hypothesised that the associations between vitamin D and serum lipids may be more pronounced in vitamin D-deficient individuals ${ }^{(18)}$, we tested the hypothesis that associations may only occur at lower $25(\mathrm{OH}) \mathrm{D}_{3}$ levels.

\section{Methods}

\section{Study population and design}

Participants were drawn from an ongoing cohort study in which the nutrition and health status of senior citizens in Giessen (GISELA), Germany (latitude $50 \cdot 6^{\circ} \mathrm{N}$ ) have been observed at annual intervals since 1994 and at biannual intervals since 1998. The GISELA study is a nonintervening observational study. The investigations took place at the Institute of Nutritional Science in Giessen, Germany. Participants were recruited by physicians, notices, senior citizens' meetings, advertisements in local newspapers and through individuals who had already participated. Recruitment was continued until 2004 with a total number of 584 participants enrolled. Not all individuals participated in each follow-up. For enrolment, individuals had to be at least 60 years of age and physically mobile. The study was conducted according to the guidelines laid down in the Declaration of Helsinki and approved by the Ethical Committee of the Faculty of Medicine at the Justus-Liebig-University, Giessen, Germany. All participants provided written informed consent.

The present investigation reports cross-sectional data that were obtained in the summer of 2008 from July to October. Participants with missing data ( $n$ 73) on blood samples, food record, body composition, chronic kidney disease history and lifestyle factors, including time spent outdoors, physical activity and smoking history, were excluded, as were those who suffered from chronic kidney disease ( $n$ 5). In addition, two elderly people were excluded because their TAG concentrations were $>400 \mathrm{mg} / \mathrm{dl}$ and two elderly people were identified as outliers due to their deviation from the mean values of the cohort and/or from the normal distribution of the residuals of the regression analyses (one person with an iPTH value of $0.6 \mathrm{pmol} / 1$ and one with a LDL-C:HDL-C of 5.4 as well as a TC:HDL-C of 8.2 ) and were therefore not included. Of the 275 elderly people who took part in the follow-up in 2008, data from 138 women and fifty-five men were included in the following analysis.

\section{Antbropometric data and body composition}

BMI was calculated as the measured weight in kilograms divided by the square of the measured body height in metres $^{(11)}$. Waist circumference (WC) was determined in an upright position by a tape measure to the nearest $1.0 \mathrm{~cm}$. The percentage of total body fat (\%TBF) was recorded by a single-frequency $(50 \mathrm{kHz})$ bioelectrical impedance analyser (Akern-RJL BIA 101/S; Data Input, Frankfurt, Germany) according to the manufacturer's instructions and the predictive formula from Roubenoff et $a l^{(19)}$.

\section{Laboratory measurements}

Blood samples were collected after an overnight fast and immediately centrifuged, aliquoted and frozen at $-70^{\circ} \mathrm{C}$ until further analysis. Serum concentrations of both $25(\mathrm{OH}) \mathrm{D}_{3}$ and iPTH were measured by an electrochemiluminescence immunoassay (Roche Diagnostics $\mathrm{GmbH}$, Mannheim, Germany) in the Limbach Laboratory, Heidelberg, Germany, which participates in the Vitamin D External Quality Assessment Scheme (DEQAS). This assay has been standardised against LC-MS/MS ${ }^{(20)}$. The CV for the total analytic precision of this assay was $\leq 9.9 \%$ for $25(\mathrm{OH}) \mathrm{D}_{3}$ and $\leq 5.9 \%$ for iPTH ${ }^{(20,21)}$. The lower detection limit of this assay was $10.0 \mathrm{nmol} / 1$ for $25(\mathrm{OH}) \mathrm{D}_{3}$ and $0.127 \mathrm{pmol} / 1$ for iPTH. Concentrations of $25(\mathrm{OH}) \mathrm{D}_{3}$ $<25 \mathrm{nmol} / \mathrm{l}$ were defined as vitamin D deficiency ${ }^{(22)}$. Due to the lack of an international consensus on optimal $25(\mathrm{OH}) \mathrm{D}_{3}$ status, we applied two $25(\mathrm{OH}) \mathrm{D}_{3}$ cut-off values as adequate $\left(\geq 50 \mathrm{nmol} / \mathrm{l}^{(23)}\right.$ and $\left.\geq 75 \mathrm{nmol} / \mathrm{l}^{(24)}\right)$. The fasting serum concentrations of TAG, TC and HDL-C (after precipitation with phosphotungstic acid and $\mathrm{Mg}^{2+}$ ions) were measured using commercial enzymatic methods, such as GPO-PAP for TAG and CHOD-PAP for TC and HDL-C, according to the manufacturer's procedures (Roche Diagnostics $\mathrm{GmbH}$ ). The cut-off values for elevated TAG and TC levels were set at $\geq 200 \mathrm{mg} / \mathrm{dl}$ and $\geq 240 \mathrm{mg} / \mathrm{dl}$, respectively, whereas HDL-C levels $<50 \mathrm{mg} / \mathrm{dl}$ and $<40 \mathrm{mg} / \mathrm{dl}$ were classified as low for women and men, respectively ${ }^{(25-27)}$. The levels of LDL-C were indirectly ascertained by the Friedewald equation ${ }^{(28)}$ as follows: $\mathrm{LDL}-\mathrm{C}=\mathrm{TC}-\mathrm{HDL}-\mathrm{C}-\mathrm{TAG} / 5$; all participants had TAG levels $<400 \mathrm{mg} / \mathrm{dl}$. LDL-C concentrations $\geq 160 \mathrm{mg} / \mathrm{dl}$ were considered as elevated ${ }^{(27)}$. In addition, ratios of LDL-C to HDL-C and TC to HDL-C were determined.

\section{Lifestyle factors}

Intakes of vitamin D, SFA and alcohol were determined by a $3 \mathrm{~d}$ estimated dietary record, which was developed and validated for the GISELA study ${ }^{(29)}$. This record did not assess 
nutrient intake from supplements. Using self-administered questionnaires data on age, time spent outdoors, smoking behaviour, physical activity patterns, diseases, medications and vitamin D supplement intake were collected. We assessed the daily time spent outdoors as a proxy for the daily sun exposure by asking the following question: 'Please estimate, how much time do you currently spend outdoors in minutes per day?' The smoking behaviour was classified as a dichotomous variable in constant non-smoker $v$. current and ex-smoker. The use of lipid-modifying drugs and the intake of vitamin D supplements were also coded as dichotomous variables (no/yes). The physical activity level (PAL) of each participant was assessed as described elsewhere $^{(30)}$.

\section{Statistical analysis}

The characteristics of the study population were expressed as medians and 5th-95th percentiles due to non-normally distributed data, which was tested by the KolmogorovSmirnov test. Descriptive characteristics were compared between groups via the Mann-Whitney $U$ test for continuous variables and via the $\chi^{2}$ test or Fisher's exact test for categorical variables.

At first, we examined univariate associations of either $25(\mathrm{OH}) \mathrm{D}_{3}$ or $\mathrm{iPTH}$ as the independent variable with the respective serum lipid as the dependent variable. Subsequently, stepwise multiple regression analyses were performed with serum concentrations of $25(\mathrm{OH}) \mathrm{D}_{3}$ and iPTH simultaneously included as fixed independent variables in each of the models and the respective serum lipid as the dependent variable. Sex, age, \%TBF, PAL, time spent outdoors, intake of SFA, vitamin D and alcohol, smoking behaviour and the use of lipid-modifying drugs were considered as covariates and were allowed to remain in the model with a $P$ value $\leq 0 \cdot 100$. In consideration of the observed collinearity of BMI, WC and \%TBF (data not shown), the variable that showed the strongest association with serum lipids was added as a potential confounder to the regression model. Effect modification by sex was evaluated by stratified analyses and tests for statistical interaction by adding product terms ( $\mathrm{sex} \times 25(\mathrm{OH}) \mathrm{D}_{3}$ and sex $\times$ iPTH) into the multiple regression analyses, respectively. Because of skewed distributions, TAG and HDL-C were logarithmically transformed $\left(\log _{10}\right)$.

Finally, we examined whether the associations between $25(\mathrm{OH}) \mathrm{D}_{3}$ and serum lipids differed between participants with $25(\mathrm{OH}) \mathrm{D}_{3}$ levels below and above the sex-specific median $25(\mathrm{OH}) \mathrm{D}_{3}$ status by using stepwise multiple regression analyses with adjustments for age, \%TBF, PAL, alcohol consumption, smoking behaviour, use of lipid-modifying drugs and $\mathrm{iPTH}$. The median $25(\mathrm{OH}) \mathrm{D}_{3}$ status was used as cut-off value to get two groups almost equal in size.

Statistical analyses were conducted using the statistical software package IBM SPSS ${ }^{\circledR}$ Statistics version 21.0 for Windows. The significance level was set at $P<0.05$, and two-sided.

\section{Results}

\section{Characteristics of the study participants}

The characteristics of the study participants are shown in Table 1 . None of the participants were vitamin D-deficient, but $20.7 \%$ had $25(\mathrm{OH}) \mathrm{D}_{3}$ levels $<50 \mathrm{nmol} / \mathrm{l}$ and $20.7 \%$ had $25(\mathrm{OH}) \mathrm{D}_{3}$ levels $\geq 75 \mathrm{nmol} / \mathrm{l}$. Hyperparathyroidism, which was defined as iPTH levels $>6.9 \mathrm{pmol} / 1$, was found in $15.5 \%$ of the participants. Of the study population, $6 \cdot 2 \%, 13.5 \%$ and $7 \cdot 3 \%$ had elevated levels of TAG, TC and LDL-C, respectively, and $24.9 \%$ showed low HDL-C levels. No significant sex differences were observed in any of these analyses (data not shown).

No differences in serum lipid concentrations were found between participants who had $25(\mathrm{OH}) \mathrm{D}_{3}$ levels of $\geq 50 \mathrm{nmol} / 1$ and $<50 \mathrm{nmol} / 1$. In contrast, the ratios of LDLC:HDL-C (median: 1.96 v. 2.21;P=0.022) and TC:HDL-C (median: $3.28 v .3 \cdot 68 ; P=0.031$ ) were significantly lower in participants with $25(\mathrm{OH}) \mathrm{D}_{3}$ concentrations $\geq 75 \mathrm{nmol} / \mathrm{l}$ compared with those who had lower $25(\mathrm{OH}) \mathrm{D}_{3}$ levels.

Participants with dyslipidaemia (low HDL-C levels, elevated levels of TAG, TC and/or LDL-C) or participants who used lipid-modifying drugs did not differ in their prevalence of vitamin $\mathrm{D}$ insufficiency $\left(25(\mathrm{OH}) \mathrm{D}_{3}\right.$ levels $<50$ or $<75 \mathrm{nmol} / \mathrm{l}$ ) from those who showed normal lipid profiles or did not use lipid-modifying drugs. However, participants with dyslipidaemia had lower $25(\mathrm{OH}) \mathrm{D}_{3}$ levels than those with lipid concentrations in the reference range (median: 59.9 v. $65.5 \mathrm{nmol} / \mathrm{l} ; P=0.017$ ). The use of lipid-modifying drugs had no impact on $25(\mathrm{OH}) \mathrm{D}_{3}$ in the sex- and age-adjusted regression analysis (data not shown).

\section{Univariate and multiple regression analyses of 25-bydroxycholecalciferol and intact paratbyroid bormone with serum lipids and lipid ratios for the entire study population and stratified by sex}

The results of the univariate regression analyses regarding the associations of $25(\mathrm{OH}) \mathrm{D}_{3}$ and $\mathrm{iPTH}$ with serum lipids are given in Table 2 . Serum $25(\mathrm{OH}) \mathrm{D}_{3}$ was positively associated with log HDL-C and negatively associated with ratios of LDL-C:HDL-C and TC:HDL-C in women and in the pooled analysis of women and men together. In addition, serum $25(\mathrm{OH}) \mathrm{D}_{3}$ was negatively associated with $\log$ TAG in women. Serum iPTH was negatively associated with $\log$ HDL-C in men and in the pooled analysis.

As \%TBF was more strongly associated with serum lipids than were anthropometric variables as judged by the standardised coefficient beta ( $\beta$; data not shown), and because \%TBF, but not anthropometric parameters, was an independent determinant of $25(\mathrm{OH}) \mathrm{D}_{3}$ in this cohort $^{(11)}$, the subsequent multiple regression analyses were controlled for \%TBF.

Table 3 presents the results of the multiple regression analyses for the entire study population and, in addition, stratified by sex. Substantial sex differences existed and 
Table 1 Characteristics of the study population*: well-functioning German elderly aged 66-96 years ( $n$ 193), Giessen, Germany, July-October 2008 (GISELA study)

\begin{tabular}{|c|c|c|c|c|c|}
\hline \multirow[b]{2}{*}{ Characteristic } & \multicolumn{2}{|c|}{ Women (n 138) } & \multicolumn{2}{|c|}{ Men ( $n$ 55) } & \multirow[b]{2}{*}{$P$ value } \\
\hline & Median & P5-P95 & Median & P5-P95 & \\
\hline Age (years) & $75 \cdot 0$ & $68 \cdot 0-86 \cdot 1$ & $76 \cdot 0$ & $67 \cdot 8-85 \cdot 2$ & 0.235 \\
\hline $\mathrm{BMI}\left(\mathrm{kg} / \mathrm{m}^{2}\right)$ & $27 \cdot 1$ & $21 \cdot 0-34.9$ & $26 \cdot 4$ & $22 \cdot 4-33.4$ & 0.603 \\
\hline WC (cm) & $90 \cdot 0$ & $72 \cdot 0-110 \cdot 1$ & $101 \cdot 0$ & $86 \cdot 4-119 \cdot 2$ & $<0.0001$ \\
\hline$\%$ TBF & $42 \cdot 8$ & $32 \cdot 1-50 \cdot 4$ & 29.2 & $21 \cdot 4-43 \cdot 1$ & $<0.0001$ \\
\hline $25(\mathrm{OH}) \mathrm{D}_{3}(\mathrm{nmol} / \mathrm{l})$ & $62 \cdot 3$ & $39 \cdot 0-92 \cdot 9$ & 65.6 & $39 \cdot 1-89 \cdot 7$ & 0.234 \\
\hline iPTH (pmol/l) & 4.6 & $2.5-11.6$ & 4.5 & $2 \cdot 3-13 \cdot 0$ & 0.794 \\
\hline TAG (mg/dl) & $112 \cdot 2$ & $54 \cdot 7-222 \cdot 3$ & 92.4 & $52 \cdot 5-230 \cdot 2$ & 0.047 \\
\hline TC $(\mathrm{mg} / \mathrm{dl})$ & $210 \cdot 6$ & $154 \cdot 8-263 \cdot 6$ & $188 \cdot 4$ & $123 \cdot 3-247 \cdot 3$ & $<0.0001$ \\
\hline HDL-C (mg/dl) & 60.3 & $39 \cdot 2-87 \cdot 4$ & $49 \cdot 0$ & $32 \cdot 3-73 \cdot 3$ & $<0.0001$ \\
\hline LDL-C (mg/dl) & $125 \cdot 8$ & $76 \cdot 8-165 \cdot 5$ & $114 \cdot 7$ & $59 \cdot 7-165 \cdot 7$ & 0.046 \\
\hline LDL-C:HDL-C & $2 \cdot 1$ & $1 \cdot 2-3 \cdot 6$ & $2 \cdot 3$ & $1 \cdot 2-3 \cdot 7$ & 0.178 \\
\hline TC:HDL-C & 3.5 & $2 \cdot 4-5 \cdot 3$ & 3.7 & $2 \cdot 3-5 \cdot 9$ & $0 \cdot 171$ \\
\hline SFA intake (g/d) & $26 \cdot 7$ & $11 \cdot 7-51 \cdot 6$ & 28.5 & $17 \cdot 8-58 \cdot 6$ & 0.093 \\
\hline Vitamin D intake $(\mu \mathrm{g} / \mathrm{d})$ & 3.0 & $0.4-10.5$ & 4.7 & $0.9-15.8$ & 0.069 \\
\hline Alcohol intake $(\mathrm{g} / \mathrm{d})$ & 0.5 & $0.0-21.4$ & $5 \cdot 1$ & $0 \cdot 0-27 \cdot 0$ & 0.008 \\
\hline Time spent outdoors $(\mathrm{min} / \mathrm{d})$ & $120 \cdot 0$ & $39 \cdot 5-360 \cdot 0$ & $120 \cdot 0$ & $36 \cdot 0-504 \cdot 0$ & 0.019 \\
\hline \multirow[t]{2}{*}{ PAL } & $1 \cdot 7$ & $1 \cdot 5-2 \cdot 0$ & $1 \cdot 6$ & $1.4-1.9$ & 0.153 \\
\hline & $n$ & $\%$ & $n$ & $\%$ & \\
\hline Current or ex-smokers & 33 & 23.9 & 37 & $67 \cdot 3$ & $<0.0001$ \\
\hline Vitamin D supplement users & 20 & 14.5 & 3 & 5.5 & 0.080 \\
\hline Lipid-modifying drugs & 34 & 24.6 & 14 & $25 \cdot 5$ & 0.906 \\
\hline Dyslipidaemiał & 55 & 39.9 & 17 & 30.9 & 0.246 \\
\hline
\end{tabular}

WC, waist circumference; \%TBF, percentage of total body fat; $25(\mathrm{OH}) \mathrm{D}_{3}$, 25-hydroxycholecalciferol (25-hydroxyvitamin $\mathrm{D}_{3}$ ); iPTH, intact parathyroid hormone; TC, total cholesterol; HDL-C, HDL cholesterol; LDL-C, LDL cholesterol; PAL, physical activity level.

*Data are presented as median and 5th-95th percentiles (P5-P95) for continuous variables and as absolute and relative frequencies for categorical variables. †Mann-Whitney $U$ test for continuous variables, $x^{2}$ test for categorical variables.

$\ddagger$ The term dyslipidaemia refers to participants with serum levels of TAG $\geq 200 \mathrm{mg} / \mathrm{dl}$, TC $\geq 240 \mathrm{mg} / \mathrm{dl}$, LDL-C $\geq 160 \mathrm{mg} / \mathrm{dl}$ and/or HDL-C $<40$ (men) and 50 (women) $\mathrm{mg} / \mathrm{dl}$, respectively.

Table 2 Univariate regression analyses of $25(\mathrm{OH}) \mathrm{D}_{3}$ and iPTH with fasting serum lipids* among well-functioning German elderly aged 66-96 years (n 193), Giessen, Germany, July-October 2008 (GISELA study)

\begin{tabular}{|c|c|c|c|c|c|c|c|c|c|c|c|c|}
\hline & \multicolumn{2}{|c|}{$\log$ TAG (mg/dl) } & \multicolumn{2}{|c|}{$\mathrm{TC}(\mathrm{mg} / \mathrm{dl})$} & \multicolumn{2}{|c|}{$\log \mathrm{HDL}-\mathrm{C}(\mathrm{mg} / \mathrm{dl})$} & \multicolumn{2}{|c|}{ LDL-C (mg/dl) } & \multicolumn{2}{|c|}{ LDL-C:HDL-C } & \multicolumn{2}{|c|}{ TC:HDL-C } \\
\hline & $\beta$ & $P$ & $\beta$ & $P$ & $\beta$ & $P$ & $\beta$ & $P$ & $\beta$ & $P$ & $\beta$ & $P$ \\
\hline \multicolumn{13}{|l|}{ Entire cohort ( $n$ 193) } \\
\hline $25(\mathrm{OH}) \mathrm{D}_{3}(\mathrm{nmol} / \mathrm{l})$ & -0.130 & 0.072 & -0.035 & 0.633 & 0.166 & 0.021 & -0.076 & 0.294 & -0.180 & 0.012 & -0.188 & 0.009 \\
\hline iPTH (pmol/l) & 0.012 & 0.865 & -0.128 & 0.077 & -0.147 & 0.041 & -0.074 & 0.304 & -0.074 & 0.304 & 0.037 & 0.609 \\
\hline \multicolumn{13}{|l|}{ Women ( $n$ 138) } \\
\hline $25(\mathrm{OH}) \mathrm{D}_{3}(\mathrm{nmol} / \mathrm{l})$ & -0.200 & 0.019 & -0.051 & 0.551 & 0.262 & 0.002 & -0.128 & 0.134 & -0.275 & 0.001 & -0.280 & $<0.001$ \\
\hline iPTH (pmol/l) & 0.037 & 0.665 & -0.062 & 0.467 & -0.081 & 0.342 & -0.024 & 0.784 & 0.026 & 0.762 & 0.029 & 0.740 \\
\hline \multicolumn{13}{|l|}{ Men $(n 55)$} \\
\hline $25(\mathrm{OH}) \mathrm{D}_{3}(\mathrm{nmol} / \mathrm{l})$ & 0.049 & 0.721 & 0.071 & 0.605 & 0.052 & 0.709 & 0.069 & 0.617 & 0.069 & 0.617 & 0.0005 & 0.997 \\
\hline iPTH (pmol/l) & -0.025 & 0.857 & -0.234 & 0.085 & -0.294 & 0.029 & -0.155 & 0.259 & 0.050 & 0.716 & 0.050 & 0.716 \\
\hline
\end{tabular}

$25(\mathrm{OH}) \mathrm{D}_{3}, 25$-hydroxycholecalciferol (25-hydroxyvitamin $\mathrm{D}_{3}$ ); iPTH, intact parathyroid hormone; TC, total cholesterol; HDL-C, HDL cholesterol; LDL-C, LDL cholesterol.

*The results of the analyses are expressed in terms of the standardised coefficient beta ( $\beta$ ).

effect modification by sex was significant with respect to $\log$ HDL-C, LDL-C and LDL-C:HDL-C $(P<0 \cdot 05)$. In women, $25(\mathrm{OH}) \mathrm{D}_{3}$ was a predictor of $\log \mathrm{TAG}, \log \mathrm{HDL}-\mathrm{C}, \mathrm{LDL}-\mathrm{C}$ : HDL-C and TC:HDL-C, whereas, in men, iPTH was a negative predictor of log HDL-C after adjusting for age, \%TBF, PAL, alcohol consumption, smoking behaviour and the use of lipid-modifying drugs. Except for the association between $\mathrm{PTH}$ and TC in men, which became significant $(\beta=-0 \cdot 281 ; P=0.035)$, these results remained essentially unchanged after additional adjustment for time spent outdoors, intake of SFA, dietary vitamin D intake and use of vitamin D supplements (data not shown). Because $25(\mathrm{OH}) \mathrm{D}_{3}$ was associated with serum lipids only in women, the following sub-analysis was restricted to female participants.

\section{Associations between 25-hydroxycholecalciferol and serum lipids stratified by median vitamin $D$ status in women}

In women, $25(\mathrm{OH}) \mathrm{D}_{3}$ was significantly related to TC $(\beta=-0.252 ; P=0.030), \log$ HDL-C $(\beta=0.230 ; P=0.046)$, LDL-C $(\beta=-0.324 ; P=0.006)$, LDL-C:HDL-C $(\beta=-0.412$; 
Table 3 Multiple regression analyses to scrutinise independent associations of $25(\mathrm{OH}) \mathrm{D}_{3}$ and iPTH with fasting serum lipids ${ }^{*}$ among well-functioning German elderly aged 66-96 years ( $n$ 193), Giessen, Germany, July-October 2008 (GISELA study)

\begin{tabular}{|c|c|c|c|c|c|c|c|c|c|c|c|c|}
\hline & \multicolumn{12}{|c|}{ Dependent variables } \\
\hline & \multicolumn{2}{|c|}{$\log$ TAG (mg/dl) } & \multicolumn{2}{|c|}{$\mathrm{TC}(\mathrm{mg} / \mathrm{dl})$} & \multicolumn{2}{|c|}{$\log$ HDL-C (mg/dl) } & \multicolumn{2}{|c|}{ LDL-C (mg/dl) } & \multicolumn{2}{|c|}{ LDL-C:HDL-C } & \multicolumn{2}{|c|}{ TC:HDL-C } \\
\hline & $\beta$ & $P$ & $\beta$ & $P$ & $\beta$ & $P$ & $\beta$ & $P$ & $\beta$ & $P$ & $\beta$ & $P$ \\
\hline \multicolumn{13}{|l|}{ Entire cohort $(n$ 193)† } \\
\hline $\begin{array}{l}25(\mathrm{OH}) \mathrm{D}_{3}(\mathrm{nmol} / \mathrm{l}) \\
\mathrm{iPTH}(\mathrm{pmol} / \mathrm{l})\end{array}$ & $\begin{array}{l}-0.071 \\
-0.048\end{array}$ & $\begin{array}{l}0.338 \\
0.503\end{array}$ & $\begin{array}{l}-0.050 \\
-0.125\end{array}$ & $\begin{array}{l}0.482 \\
0.080\end{array}$ & $\begin{array}{r}0.153 \\
-0.070\end{array}$ & $\begin{array}{l}0.032 \\
0.301\end{array}$ & $\begin{array}{l}-0.087 \\
-0.014\end{array}$ & $\begin{array}{l}0.238 \\
0.863\end{array}$ & $\begin{array}{l}-0.200 \\
-0.037\end{array}$ & $\begin{array}{l}0.009 \\
0.621\end{array}$ & $\begin{array}{l}-0.193 \\
-0.018\end{array}$ & $\begin{array}{l}0.010 \\
0.813\end{array}$ \\
\hline$R^{2}$ entire cohort & & & & & \multicolumn{2}{|c|}{0.211} & & & \multicolumn{2}{|c|}{0.052} & \multicolumn{2}{|c|}{0.025} \\
\hline \multicolumn{13}{|l|}{ Women (n 138)‡ } \\
\hline $25(\mathrm{OH}) \mathrm{D}_{3}(\mathrm{nmol} / \mathrm{l})$ & -0.180 & 0.040 & -0.080 & 0.380 & 0.197 & 0.027 & -0.152 & 0.094 & -0.298 & $<0.001$ & -0.302 & $<0.001$ \\
\hline iPTH (pmol/l) & -0.071 & 0.390 & -0.088 & 0.332 & 0.034 & 0.690 & -0.072 & 0.422 & -0.070 & 0.423 & -0.069 & 0.430 \\
\hline$R^{2}$ women & \multirow{2}{*}{\multicolumn{2}{|c|}{$0 \cdot 184$}} & & & \multicolumn{2}{|c|}{0.149} & & & \multicolumn{2}{|c|}{0.067} & \multicolumn{2}{|c|}{0.069} \\
\hline Men $(n 55) \ddagger$ & & & & & & & & & & & & \\
\hline $25(\mathrm{OH}) \mathrm{D}_{3}(\mathrm{nmol} / \mathrm{l})$ & 0.046 & 0.747 & -0.061 & 0.660 & -0.012 & 0.930 & -0.064 & 0.639 & -0.071 & 0.615 & $0 \cdot 109$ & 0.455 \\
\hline iPTH $(\mathrm{pmol} / \mathrm{l})$ & -0.015 & 0.916 & -0.252 & 0.063 & -0.297 & 0.033 & -0.175 & 0.189 & 0.030 & 0.826 & 0.064 & 0.643 \\
\hline$R^{2}$ men & & & & & 0.0 & & & & & & & \\
\hline
\end{tabular}

25(OH) $\mathrm{D}_{3}$, 25-hydroxycholecalciferol (25-hydroxyvitamin $\mathrm{D}_{3}$ ); iPTH, intact parathyroid hormone; TC, total cholesterol; HDL-C, HDL cholesterol; LDL-C, LDL cholesterol; \%TBF, percentage of total body fat; PAL, physical activity level.

${ }^{*}$ Multiple linear regression analyses were performed using stepwise procedure and the respective serum lipid as dependent variable. Serum $25(\mathrm{OH}) \mathrm{D}_{3}$ and iPTH concentrations were simultaneously included as fixed independent variables in each of the models. The results of the analyses are expressed in terms of the standardised coefficient beta $(\beta)$ and the adjusted coefficient of determination $\left(R^{2}\right)$ for the final model provided that the association of $25(\mathrm{OH}) \mathrm{D}_{3}$ or iPTH with serum lipids reached statistical significance.

†Adjusted for sex, sex interaction (sex $\times 25(\mathrm{OH}) \mathrm{D}_{3}$ and sex $\left.\times \mathrm{iPTH}\right)$, age, \%TBF, PAL, alcohol consumption, smoking behaviour and the use of lipid-modifying drugs. Effect modification by sex was significant for log HDL-C (sex $\left.\times 25(\mathrm{OH}) \mathrm{D}_{3} ; P<0.0001\right)$, LDL-C (sex $\times$ iPTH; $\left.P=0.017\right)$ and LDL-C:HDL-C (sex $\times 25(\mathrm{OH})$ $\left.\mathrm{D}_{3} ; P=0.006\right)$.

¥Adjusted for age, \%TBF, PAL, alcohol consumption, smoking behaviour and the use of lipid-modifying drugs.

$P<0.001)$ and TC:HDL-C $(\beta=-0.380 ; P=0.001)$ in participants with $25(\mathrm{OH}) \mathrm{D}_{3}$ levels $\geq 62.3 \mathrm{nmol} / 1$ ( $n$ 69) after controlling for age, \%TBF, PAL, alcohol consumption, smoking behaviour, use of lipid-modifying drugs and iPTH. Female participants with $25(\mathrm{OH}) \mathrm{D}_{3}$ levels $<62.3 \mathrm{nmol} / \mathrm{l}$ ( $n$ 69) showed no significant associations. The results of the respective univariate regression analyses are illustrated in the online supplementary material, Supplemental Fig. 1.

\section{Discussion}

To our knowledge, the present study is the first one to investigate the associations of $25(\mathrm{OH}) \mathrm{D}_{3}$ and $\mathrm{iPTH}$ with serum lipids and lipid ratios by sex and vitamin D status in primarily non-obese, non-vitamin D-deficient, wellfunctioning German elderly. Our results indicate that: (i) $25(\mathrm{OH}) \mathrm{D}_{3}$ is associated with serum lipids only in women, whereas iPTH is associated with serum lipids only in men; and (ii) associations between $25(\mathrm{OH}) \mathrm{D}_{3}$ and serum lipids may require $25(\mathrm{OH}) \mathrm{D}_{3}$ concentrations above $62 \mathrm{nmol} / 1$ to significantly affect the serum lipid profile in women. Thus, contrary to the initial assumption, significant associations between $25(\mathrm{OH}) \mathrm{D}_{3}$ and serum lipids may not be restricted to a low/insufficient vitamin D status. However, we cannot exclude that the true threshold level of $25(\mathrm{OH}) \mathrm{D}_{3}$ is below or above $62 \mathrm{nmol} / 1$ or that vitamin D-deficient individuals show associations as well, because none of our participants had a severe vitamin D deficiency. Supplemental Fig. 1 (see online supplementary material) illustrates that non-linear relationships may exist, which could explain the conflicting results in the literature. In this context, one might speculate whether there is an association in deficient and sufficient stages and no significant association at concentrations between 25 and about $60 \mathrm{nmol} / \mathrm{l}$.

The reason why $25(\mathrm{OH}) \mathrm{D}_{3}$ was positively associated with HDL-C and negatively associated with TAG, LDL-C: HDL-C and TC:HDL-C only in women, whereas iPTH showed a negative relationship with TC and HDL-C only in men, is unknown. Possibly, the sex differences in HDL-C levels and in the amount and distribution of body fat act as confounders. Next to sex, \%TBF was one of the strongest predictors of serum lipids in our cohort (data not shown), and an inverse association between $\% \mathrm{TBF}$ and $25(\mathrm{OH}) \mathrm{D}_{3}$ was observed only in the female participants of the GISELA study ${ }^{(11)}$. Obesity is an established risk factor of dyslipidaemia ${ }^{(10)}$ and may negatively impact circulating $25(\mathrm{OH}) \mathrm{D}_{3}$ levels $^{(11)}$ due to a sequestration of vitamin $\mathrm{D}$ in adipose tissue or, alternatively, a volumetric dilution effect ${ }^{(31)}$. Thus, a confounding effect of TBF seems likely. However, the greater sample size of women compared with men may have led to the observed sex differences.

Previous studies have reported conflicting findings regarding the associations between vitamin $\mathrm{D}, \mathrm{iPTH}$ and serum lipids. For instance, in the Framingham Offspring Study, age- and sex-adjusted associations between 25-hydroxyvitamin D (25(OH)D) and TAG and HDL-C were reported in 678 individuals (mean age of 59.6 (SD 0.3) years) 
not using cholesterol-lowering medications, but these associations vanished after additional adjustments for BMI, WC and smoking ${ }^{(8)}$. In the National Health and Nutrition Examination Survey, an independent association between $25(\mathrm{OH}) \mathrm{D}$ and HDL-C was reported ${ }^{(4,5)}$, but no associations between 25(OH)D and TAG or LDL-C ${ }^{(5)}$. In the Women's Health Initiative Calcium-Vitamin D trial, a significant inverse association between $25(\mathrm{OH}) \mathrm{D}$ and TAG was found in 292 postmenopausal women aged 50-79 years after considering potential confounders, but no associations between $25(\mathrm{OH}) \mathrm{D}$ and TC, LDL-C or HDL-C ${ }^{(32)}$. In the study by Karhapää et al. with 909 Finnish men aged 45-70 years, significant inverse associations were observed between $25(\mathrm{OH}) \mathrm{D}$ and TAG, TC and LDL-C, but no association between $25(\mathrm{OH}) \mathrm{D}$ and HDL-C was noticed after controlling for confounding factors ${ }^{(7)}$. In the Troms $\varnothing$ Study, non-fasting serum levels of TC, HDL-C and LDL-C increased, while LDL-C:HDL-C and TAG levels decreased, across $25(\mathrm{OH}) \mathrm{D}$ quartiles in 8018 non-smokers with a mean age of 55.9 (SD 12.6) years after controlling for sex, age, sample month and $\mathrm{BMI}^{(33)}$. In previous investigations, the associations between PTH and serum lipids were less often examined and frequently no independent relationships were found $^{(5,12)}$. In our male participants, $\mathrm{iPTH}$ remained a negative predictor of HDL-C even after controlling for relevant confounders. The consideration of different confounders and the fact that some studies examined only one sex and others analysed women and men together without considering potential effect modifications by sex may be partly responsible for the inconsistent results. Furthermore, as indicated by our results, the vitamin $\mathrm{D}$ status of an individual might also be an important factor in this context.

The associations between 25(OH)D concentrations and serum lipids point towards a potentially favourable effect of vitamin D supplements on CVD risk markers. However, the majority of previous intervention trials did not report a significant increase in HDL-C or a decrease in unfavourable serum lipids, such as TAG, TC or LDL-C, due to vitamin D supplementation ${ }^{(34-36)}$. A recent meta-analysis of twelve randomised controlled trials evaluated the effects of vitamin D supplements on blood lipids and indicated that vitamin D supplementation could increase LDL-C levels, but may not have statistically significant effects on TAG, TC or HDL-C ${ }^{(37)}$. In our study, neither the use of vitamin D supplements nor the dietary intake levels of vitamin D were significantly associated with serum lipids after adjusting for sex, age, \%TBF, iPTH, PAL, time spent outdoors, intake of SFA and alcohol, smoking behaviour and the use of lipid-modifying drugs (data not shown). Considering the low vitamin D intake and the low percentage of supplement users in our study, these amounts may have been insufficient to affect $25(\mathrm{OH}) \mathrm{D}_{3}$ levels ${ }^{(11)}$ and, consequently, to influence concentrations of serum lipids. Moreover, in a previous study, we could show that the use of vitamin D supplements was associated with $25(\mathrm{OH}) \mathrm{D}_{3}$ levels in individuals with a
BMI $<25 \mathrm{~kg} / \mathrm{m}^{2(38)}$, but not in those with a higher BMI. The higher TBF may decrease the bioavailability of vitamin $D$ and thus may constrain favourable effects of vitamin D supplements on serum lipids. Therefore, a beneficial effect of vitamin D supplements on serum lipids cannot be excluded and may depend on dosage, vitamin D status and/or body composition.

As serum lipids represent markers for cardiovascular events and participants with dyslipidaemia had lower levels of $25(\mathrm{OH}) \mathrm{D}_{3}$ than participants with lipid concentrations in the reference range in our study, this might support the hypothesis of a protective role of $25(\mathrm{OH}) \mathrm{D}_{3}$ regarding CVD risk. At present, the mechanisms for the potential associations between vitamin D, iPTH and serum lipids still await elucidation. The vitamin D status of an individual may represent a surrogate marker of cardiovascular health ${ }^{(13)}$, but may not occupy a central position in the pathogenesis of dyslipidaemia. Some researchers considered circulating $\mathrm{Ca}$ as a causal factor for the association between vitamin D and cardiovascular risk factors ${ }^{(15)}$; whereas others stated that this association may not be mediated by circulating $\mathrm{Ca}^{(5)}$. The increased absorption of intestinal Ca due to a higher vitamin D status may reduce circulating TAG by decreasing hepatic TAG formation and secretion ${ }^{(15)}$. Alternatively, the suppression of iPTH by a high vitamin D status may result in a reduction of serum TAG by increased peripheral elimination ${ }^{(15,32)}$. Other tentative explanations are the inverse association of vitamin D with insulin resistance and the vitamin D-mediated increase in the expression of VLDL receptors ${ }^{(3,7,39)}$.

The strengths of the present study include the evaluation of different serum lipids and also lipid ratios in independently living elderly without vitamin D deficiency, the conduction of sex-specific analyses and the consideration of a variety of possible confounders as well as the application of different $25(\mathrm{OH}) \mathrm{D}_{3}$ cut-off levels. However, as with any cross-sectional study, we cannot infer causality. Our study subjects were participants of a prospective cohort study and thus not recruited by representative criteria. In general, prospective cohort studies are susceptible to attrition of participants and selection bias, especially in older cohorts. Due to the presence of missing data the sample size was relatively small and selection bias cannot be excluded as the participants were volunteers, had higher levels of education and physical activity, and were more often normal-weight and non-smokers than their peers in the general German population $^{(30)}$. We did not analyse lipoprotein particle composition, carry out apolipoprotein testing or perform adjustment for multiple testing due to the exploratory approach of our study. Further limitations are the use of self-reported data, the indirect ascertainment of sun exposure and physical activity, and missing information on the brand, exact dosage and duration of the use of vitamin D supplements and lipid-modifying drugs. Frequently, the use of immunoassays rather than LC-MS/MS for measuring $25(\mathrm{OH}) \mathrm{D}$ is a matter of dispute. Concerns have been 
raised regarding for example the interaction with other compounds, such as vitamin D-binding protein or the $\mathrm{C} 3$-epimer of $25(\mathrm{OH}) \mathrm{D}_{3}$. In addition, variations in the matrix in which the measurement is performed can influence antibody binding and may produce a random error ${ }^{(40)}$. However, our assay was standardised against LC-MS/MS ${ }^{(20)}$ and the laboratory participates in the DEQAS.

\section{Conclusions}

In conclusion, the present study indicates that the associations of $25(\mathrm{OH}) \mathrm{D}_{3}$ and $\mathrm{iPTH}$ with serum lipids may differ by sex and vitamin $\mathrm{D}$ status. The associations between $25(\mathrm{OH}) \mathrm{D}_{3}$ and lipids were predominantly observed in women, while the associations between iPTH and lipids were restricted to men. Only at $25(\mathrm{OH}) \mathrm{D}_{3}$ levels $\geq 62 \mathrm{nmol} / 1$ were associations of $25(\mathrm{OH}) \mathrm{D}_{3}$ with $\mathrm{TC}$, HDL-C, LDL-C, LDL-C:HDL-C and TC:HDL-C observed independent of body composition and lifestyle in women. Therefore, sex and vitamin D status should be taken into account when analysing potentially beneficial effects of vitamin D on CVD risk markers. In clinical practice, especially overweight and obese elderly individuals who are at risk of developing dyslipidaemia, hyperparathyroidism and vitamin D deficiency might benefit from a routine vitamin D screening and, if necessary, vitamin D supplementation, to counteract low $25(\mathrm{OH}) \mathrm{D}_{3}$ levels. Overall, an adequate vitamin D status may have an advantageous impact on dyslipidaemia in the elderly.

\section{Acknowledgements}

Sources of funding: This investigation received no specific grant from any funding agency in the public, commercial or non-profit sectors. Conflict of interest: None. Authorship: A.J. developed the study hypothesis, performed the data analyses, interpreted the data and wrote the manuscript. H.J.R. analysed the blood samples for $25(\mathrm{OH}) \mathrm{D}_{3}$ and iPTH. M.N.-B. designed the study, conducted the research and proofread the manuscript. Ethics of buman subject participation: This study was approved by the Ethical Committee of the Faculty of Medicine at the JustusLiebig-University, Giessen, Germany.

\section{Supplementary material}

To view supplementary material for this article, please visit http://dx.doi.org/10.1017/S1368980014002286

\section{References}

1. Wacker M \& Holick MF (2013) Sunlight and vitamin D: a global perspective for health. Dermato-endocrinology $\mathbf{5}$, 51-108.
2. Martins D, Wolf M, Pan D et al. (2007) Prevalence of cardiovascular risk factors and the serum levels of 25-hydroxyvitamin D in the United States: data from the Third National Health and Nutrition Examination Survey. Arch Intern Med 167, 1159-1165.

3. Chiu KC, Chu A, Go VL et al. (2004) Hypovitaminosis D is associated with insulin resistance and $\beta$ cell dysfunction. $\mathrm{Am}$ J Clin Nutr 79, 820-825.

4. Forrest KY \& Stuhldreher WL (2011) Prevalence and correlates of vitamin D deficiency in US adults. Nutr Res 31, $48-54$.

5. Fraser A, Williams D \& Lawlor DA (2010) Associations of serum 25-hydroxyvitamin D, parathyroid hormone and calcium with cardiovascular risk factors: analysis of 3 NHANES cycles (2001-2006). PLoS One 5, e13882.

6. Gannagé-Yared MH, Chedid R, Khalife S et al. (2009) Vitamin $\mathrm{D}$ in relation to metabolic risk factors, insulin sensitivity and adiponectin in a young Middle-Eastern population. Eur J Endocrinol 160, 965-971.

7. Karhapää P, Pihlajamäki J, Pörsti I et al. (2010) Diverse associations of 25-hydroxyvitamin D and 1,25-dihydroxyvitamin D with dyslipidaemias. J Intern Med 268, 604-610.

8. Liu E, Meigs JB, Pittas AG et al. (2009) Plasma 25-hydroxyvitamin $\mathrm{D}$ is associated with markers of the insulin resistant phenotype in nondiabetic adults. $J$ Nutr 139, 329-334.

9. Kamycheva E, Sundsfjord J \& Jorde R (2004) Serum parathyroid hormone levels predict coronary heart disease: the Tromsø Study. Eur J Cardiovasc Prev Rehabil 11, 69-74.

10. Nguyen NT, Magno CP, Lane KT et al. (2008) Association of hypertension, diabetes, dyslipidemia, and metabolic syndrome with obesity: findings from the National Health and Nutrition Examination Survey, 1999 to 2004. J Am Coll Surg 207, 928-934.

11. Jungert A, Roth HJ \& Neuhäuser-Berthold M (2012) Serum 25-hydroxyvitamin $\mathrm{D}_{3}$ and body composition in an elderly cohort from Germany: a cross-sectional study. Nutr Metab (Lond) 9, 42 .

12. Hjelmesaeth J, Hofs $\varnothing$ D, Aasheim ET et al. (2009) Parathyroid hormone, but not vitamin $\mathrm{D}$, is associated with the metabolic syndrome in morbidly obese women and men: a cross-sectional study. Cardiovasc Diabetol 8, 7 .

13. Ponda MP, Huang X, Odeh MA et al. (2012) Vitamin D may not improve lipid levels: a serial clinical laboratory data study. Circulation 126, 270-277.

14. Wehr E, Pilz S, Schweighofer N et al. (2009) Association of hypovitaminosis $\mathrm{D}$ with metabolic disturbances in polycystic ovary syndrome. Eur J Endocrinol 161, 575-582.

15. Zittermann A, Frisch S, Berthold HK et al. (2009) Vitamin D supplementation enhances the beneficial effects of weight loss on cardiovascular disease risk markers. Am J Clin Nutr 89, 1321-1327.

16. Gobal FA \& Mehta JL (2010) Management of dyslipidemia in the elderly population. Ther Adv Cardiovasc Dis $\mathbf{4}, 375-383$.

17. Hayes DP (2010) Vitamin D and ageing. Biogerontology 11, $1-16$.

18. Jorde R \& Grimnes G (2011) Vitamin D and metabolic health with special reference to the effect of vitamin $D$ on serum lipids. Prog Lipid Res 50, 303-312.

19. Roubenoff R, Baumgartner RN, Harris TB et al. (1997) Application of bioelectrical impedance analysis to elderly populations. J Gerontol A Biol Sci Med Sci 52, M129-M136.

20. Roche Diagnostics GmbH (2007) Elecsys and Cobas Analyzer. Vitamin D3 (25-OH). Mannheim: Roche Diagnostics GmbH.

21. Roche Diagnostics GmbH (2003) Elecsys 1010/2010/ Modular Analytics E170. PTH. Mannheim: Roche Diagnostics GmbH.

22. Rizzoli R, Boonen S, Brandi ML et al. (2013) Vitamin D supplementation in elderly or postmenopausal women: a 
2013 update of the 2008 recommendations from the European Society for Clinical and Economic Aspects of Osteoporosis and Osteoarthritis (ESCEO). Curr Med Res Opin 29, 305-313.

23. Ross AC, Manson JE, Abrams SA et al. (2011) The 2011 report on dietary reference intakes for calcium and vitamin D from the Institute of Medicine: what clinicians need to know. J Clin Endocrinol Metab 96, 53-58.

24. Holick MF, Binkley NC, Bischoff-Ferrari HA et al. (2011) Evaluation, treatment, and prevention of vitamin D deficiency: an Endocrine Society clinical practice guideline. J Clin Endocrinol Metab 96, 1911-1930.

25. Roche Diagnostics GmbH (2011) Triglycerides GPO-PAP. Mannheim: Roche Diagnostics GmbH.

26. Roche Diagnostics GmbH (2011) Cholesterol CHOD-PAP. Mannheim: Roche Diagnostics GmbH.

27. National Cholesterol Education Program (NCEP) Expert Panel on Detection, Evaluation, and Treatment of High Blood Cholesterol in Adults (Adult Treatment Panel III) (2002) Third Report of the National Cholesterol Education Program (NCEP) Expert Panel on Detection, Evaluation, and Treatment of High Blood Cholesterol in Adults (Adult Treatment Panel III) final report. Circulation 106, 3143-3421.

28. Friedewald WT, Levy RI \& Fredrickson DS (1972) Estimation of the concentration of low-density lipoprotein cholesterol in plasma, without use of the preparative ultracentrifuge. Clin Chem 18, 499-502.

29. Lührmann PM, Herbert BM, Gaster C et al. (1999) Validation of a self-administered 3-day estimated dietary record for use in the elderly. Eur J Nutr 38, 235-240.

30. Krems C, Lührmann PM \& Neuhäuser-Berthold M (2004) Physical activity in young and elderly subjects. J Sports Med Phys Fitness 44, 71-76.

31. Drincic AT, Armas LA, van Diest EE et al. (2012) Volumetric dilution, rather than sequestration best explains the low vitamin D status of obesity. Obesity (Silver Spring) 20, 1444-1448.
32. Chacko SA, Song Y, Manson JE et al. (2011) Serum 25-hydroxyvitamin D concentrations in relation to cardiometabolic risk factors and metabolic syndrome in postmenopausal women. Am J Clin Nutr 94, 209-217.

33. Jorde R, Figenschau Y, Hutchinson M et al. (2010) High serum 25-hydroxyvitamin D concentrations are associated with a favorable serum lipid profile. Eur J Clin Nutr 64, $1457-1464$.

34. Jorde R, Sneve M, Torjesen P et al. (2010) No improvement in cardiovascular risk factors in overweight and obese subjects after supplementation with vitamin $\mathrm{D}_{3}$ for 1 year. J Intern Med 267, 462-472.

35. Maki KC, Rubin MR, Wong LG et al. (2011) Effects of vitamin D supplementation on 25-hydroxyvitamin D, high-density lipoprotein cholesterol, and other cardiovascular disease risk markers in subjects with elevated waist circumference. Int J Food Sci Nutr 62, 318-327.

36. Rajpathak SN, Xue X, Wassertheil-Smoller S et al. (2010) Effect of $5 \mathrm{y}$ of calcium plus vitamin D supplementation on change in circulating lipids: results from the Women's Health Initiative. Am J Clin Nutr 91, 894-899.

37. Wang H, Xia N, Yang Y et al. (2012) Influence of vitamin D supplementation on plasma lipid profiles: a meta-analysis of randomized controlled trials. Lipids Health Dis 11, 42.

38. Jungert A \& Neuhäuser-Berthold M (2013) Dietary vitamin D intake is not associated with 25 -hydroxyvitamin $D_{3}$ or parathyroid hormone in elderly subjects, whereas the calcium-to-phosphate ratio affects parathyroid hormone. Nutr Res 33, 661-667.

39. Kohno M, Takahashi S, Oida K et al. (1997) $1 \alpha$, 25-Dihydroxyvitamin $\mathrm{D}_{3}$ induces very low density lipoprotein receptor mRNA expression in HL-60 cells in association with monocytic differentiation. Atherosclerosis 133, 45-49.

40. Binkley N, Krueger DC, Morgan S et al. (2010) Current status of clinical 25-hydroxyvitamin D measurement: an assessment of between-laboratory agreement. Clin Chim Acta 411, 1976-1982. 